\title{
Preparation of Titanium Metal Using Titanium Suboxides in Molten Salt
}

\author{
Ma Tongxiang, Hu Mengjun, Lai Pingsheng, Wen Liangying and Hu Meilong* \\ College of Materials Science and Engineering, Chongqing University, Chongqing, 400044, China
}

Perovskite is an inevitable phase formed in the cathode during electrolytic deoxidation using titanium dioxide as the raw material by FFC process. Here, titanium suboxides $\left(\mathrm{Ti}_{3} \mathrm{O}_{5}, \mathrm{Ti}_{2} \mathrm{O}_{3}\right.$ and $\left.\mathrm{TiO}\right)$ are used as the raw materials to study whether perovskite can be avoided in the process. The results show that there is not perovskite formed during electrolysis using $\mathrm{TiO}$ and perovskite is appeared in the cathode when $\mathrm{Ti}_{3} \mathrm{O}_{5}$ and $\mathrm{Ti}_{2} \mathrm{O}_{3}$ are used as the raw materials. Perovskite is formed by combining $\mathrm{Ca}^{2+}$ in the molten $\mathrm{CaCl}_{2}$ with the cathode materials after the voltage is applied between the electrodes. Perovskite is mainly produced by electrochemical deoxidation process and amount of it gradually decreases with oxygen content decreasing in the cathode. [doi:10.2320/matertrans.MA201807]

(Received September 18, 2018; Accepted November 7, 2018; Published December 14, 2018)

Keywords: molten-salt electrolysis, perovskite, titanium suboxides

\section{Introduction}

Titanium has a wide range of applications as an excellent structural and functional material. At present, the Kroll route is the main method for the preparation of titanium metal in industry. However, it has problems such as high preparation cost, complex process and serious pollution. Therefore, researchers have been seeking new technologies for efficient production of titanium. Electrolysis in molten-salt is been considered having great development prospects and has attracted worldwide attention. In 2000, Chen et al. ${ }^{1)}$ carried out the direct electrochemical reduction of titanium oxide to titanium in molten $\mathrm{CaCl}_{2}$, which named the FFC (FrayFarthing-Chen) Cambridge Process. In the FFC process, the mechanism of electro-deoxidation is that $\mathrm{TiO}_{2}$ is electrolyzed into titanium and oxygen ions at the cathode, oxygen ions are dissolved in molten $\mathrm{CaCl}_{2}$ and subsequently transferred to the anode under the electrolytic field. Finally, these ions discharged at the graphite anode in the form of $\mathrm{CO}$ or $\mathrm{CO}_{2}{ }^{2,3)}$ In the OS process, ${ }^{4-7)}$ Suzuki et al. believed that the removal of oxygen via electrochemistry can be attributed to the calcium thermal reduction. There are different explanations about the mechanism of producing titanium by electrolysis process in molten salt.

Perovskite is the inevitable phase formed in the cathode during electrolysis process of stepwise deoxidization of $\mathrm{TiO}_{2}{ }^{8-11)}$ The formation of $\mathrm{CaTiO}_{3}$ can causes expansion in the solid phase and decrease of cathode porosity, which will slows ion transport in the pores existing between the oxide particles and slow down the electrolysis speed. ${ }^{12,13)}$ In the later stage of electrolysis, reduction of $\mathrm{TiO}$ to $\mathrm{Ti}$ being another kinetically slow step. For the kinetic barrier caused by perovskite, Chen et al. studied the deoxidization effect of samples with different porosity, and found that increasing the porosity of samples can effectively reduce this barrier. ${ }^{14)}$ Therefore, one of the factors for improving the efficiency of electrolysis is to avoid the formation of perovskite as much as possible.

In all reported on electroreduction of solid oxides, such as $\mathrm{TiO}_{2},{ }^{12)} \mathrm{Nb}_{2} \mathrm{O}_{5},{ }^{15)} \mathrm{ZrO}_{2},{ }^{16)} \mathrm{Ta}_{2} \mathrm{O}_{5},{ }^{17)}$ and $\mathrm{SiO}_{2},{ }^{18)}$ calciumenriched oxide or perovskite phases of various compositions

*Corresponding author, E-mail: hml@cqu.edu.cn are observed in partially reduced cathodes. However, the mechanism of formation of these intermediate products not fully understood. There are different views on the formation mechanism of perovskites. Schwandt and Fray et al. ${ }^{19)}$ believe that during the process of electro-deoxidation of titanium dioxide, the $\mathrm{CaTiO}_{3}$ is formed when titanium dioxide was reduced to low-oxide. However, some other researchers ${ }^{20)}$ believe that part of molten salt $\mathrm{CaCl}_{2}$ can be hydrolyzed to form $\mathrm{CaO}$, which reacts with $\mathrm{TiO}_{2}$ to produced $\mathrm{CaTiO}_{3}$. In this paper, the formation mechanism of perovskites is determined by electrolysis using titanium oxides as the raw materials.

In previous studies, the results of different experiments using $\mathrm{TiO}_{2}$ as raw materials show that perovskite is formed rapidly during the deoxidation of $\mathrm{TiO}_{2}$. Figure 1 shows the xrd patterns and SEM images of $\mathrm{TiO}_{2}$ after electrolysis for 10 minutes. It shows that $\mathrm{TiO}_{2}$ reduces to $\mathrm{Ti}_{4} \mathrm{O}_{7}$ in a short time, and at the same time, perovskite is rapidly generated.

Is there perovskite formed in the cathode if titanium suboxides are used as the raw material. In this paper, the main aim is to confirm the formation mechanism of calcium titanate in the cathode and the relationship between perovskite formed and raw material used in cathode.

\section{Experimental}

\subsection{Materials and apparatus}

The cathode raw materials used in this research including $\mathrm{Ti}_{3} \mathrm{O}_{5}, \mathrm{Ti}_{2} \mathrm{O}_{3}$, TiO powder with an average size of $40 \mu \mathrm{m}-$ $50 \mu \mathrm{m}$, and was wrapped by stainless steel gauze (400 mesh) as cathode for electrolysis. Anhydrous $\mathrm{CaCl}_{2}$ of $96 \%$ specified purity, purchased from the Chengdu Hua Gong Company was the electrolyte. And the dense alumina crucible of $100 \mathrm{~mm}$ internal diameter and $100 \mathrm{~mm}$ height was placed in the vertical tubular reactor. The crucible contained approximately $600 \mathrm{~g}$ of anhydrous $\mathrm{CaCl}_{2}$ salt. The KI solution $(100 \mathrm{ml} 0.2 \mathrm{~g} / \mathrm{L}$ soluble starch and $0.08 \mathrm{~g} / \mathrm{L} \mathrm{KI})$ was prepared to detect $\mathrm{Cl}_{2}$ gas in the electrolysis process.

The Ar with purity of $99.999 \%$ was flow into the vertical tubular reactor during all these experiments, the flowrate of gas is $200 \mathrm{~mL} / \mathrm{min}$. \#304 Stainless Steel rods, $75 \mathrm{~cm}$ length, were selected as the current conductors. The dense graphite rod with purity of $99.9 \%$ and a diameter of $10 \mathrm{~mm}$ was 

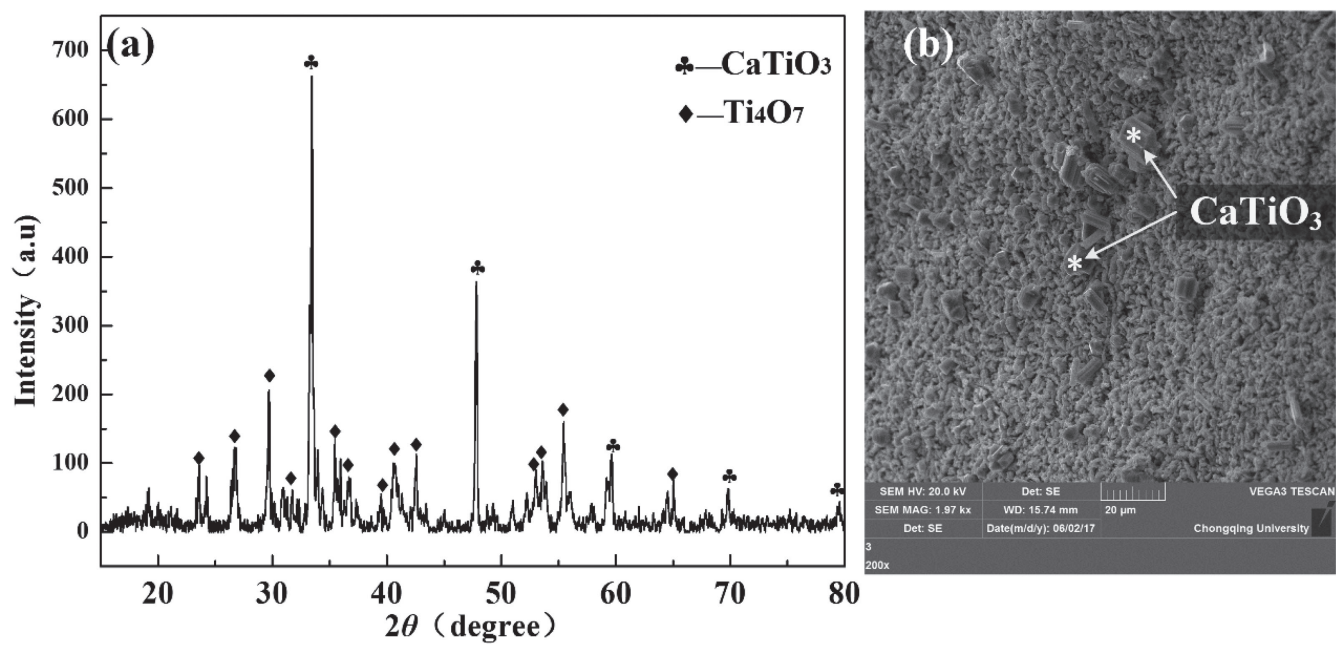

Fig. 1 (a) XRD patterns of $\mathrm{TiO}_{2}$ after electrolysis for 10 minute; (b) $\mathrm{SEM}$ image of $\mathrm{TiO}_{2}$ after electrolysis for 10 minute.

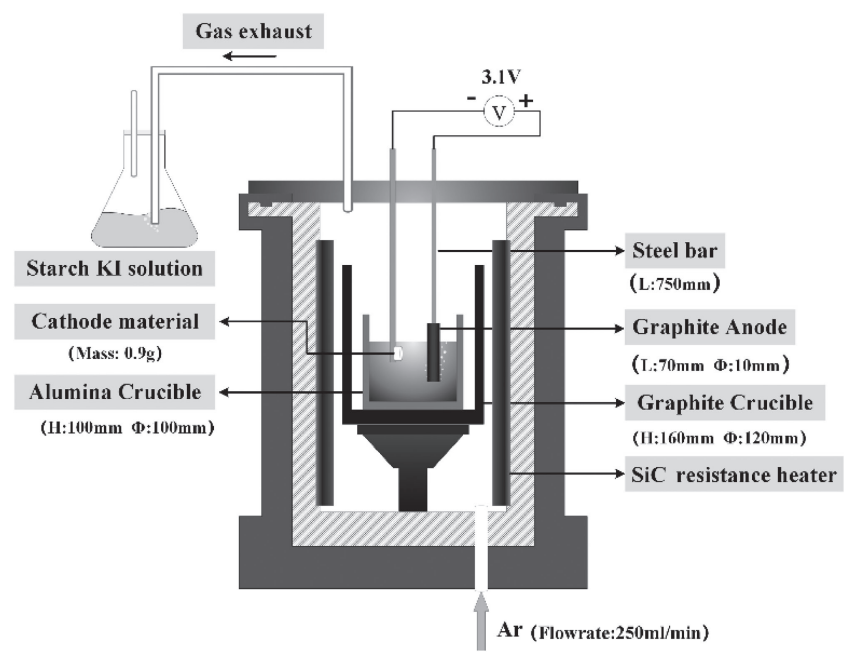

Fig. 2 Schematic of the apparatus.

connected to the steel rod by threaded connection, which was selected as the anode.

The electrolysis process was performed in a tubular electrolytic furnace (show in Fig. 2). The stainless steel lid seals the upper end of the reactor, which was equipped with holes for the electrode rods and gas outlet. Argon gas continues to be introduced into the reactor from the bottom, and the gas exhaust was led into the starch KI solution to detect the released $\mathrm{Cl}_{2}$ gas.

\subsection{Electrochemical reduction of titanium suboxides}

Put the corundum crucible into electrolytic furnace, which contains anhydrous calcium chloride, and the furnace lid was sealed. Then, the sealed reactor system was vacuumed and constantly flushed with high-purity argon gas, after the air in the furnace was completely discharged, argon gas was continuously introduced into the furnace to ensure an inert atmosphere. The furnace was heated from room temperature to $900^{\circ} \mathrm{C}$, heating rate was $10^{\circ} \mathrm{C} / \mathrm{min}$, and keep it for 30 minutes to ensure calcium chloride completely melted and the stability of the furnace temperature. After that, two stainless steel rods were inserted into molten $\mathrm{CaCl}_{2}$ as the electrode rods, a stainless steel bar with graphite bar at the bottom was used as anode, and another stainless steel rod as cathode. Then a voltage of $2.8 \mathrm{~V}$ was applied between the cathode and the anode for pre-electrolysis to remove impurities in molten salt.

The titanium suboxides powder $\left(\mathrm{Ti}_{3} \mathrm{O}_{5}, \mathrm{Ti}_{2} \mathrm{O}_{3}\right.$ and $\left.\mathrm{TiO}\right)$ was wrapped in stainless steel net as the cathode and graphite rod was used as the anode, a constant voltage of $3.1 \mathrm{~V}$ applied between the anode and the cathode. The electrochemical reduction was interrupted after different reaction times (10 minutes, 1 hourand 2 hours respectively), then the cathode was removed from the salt melt and locating it in the upper part of the reactor. The residual molten salt on the surface of the sample rapidly solidifies with decreasing temperature, and argon gas was kept in the furnace to ensure the inert atmosphere, these procedures can avoid increasing the oxygen content in sample during cooling. After cool down to room temperature naturally, put the samples into the water for several hours to remove the soluble residue $\mathrm{CaCl}_{2}$ from sample surface and then dried. Finally, the dried samples were used for the XRD and SEM analyses.

\subsection{Characterization of the cathodic products}

The phase composition of the samples was determined through X-ray diffraction analysis (XRD: D/max 2500PC). Each scan was $10^{\circ}$ to $90^{\circ}$. The microstructure and chemical composition of the samples were investigated using scanning electron microscopy (SEM, TESCAN VEGA II) and energydispersive X-ray analysis (EDS, Oxford INCA Energy 350). The acceleration voltage was $15 \mathrm{eK}$.

\section{Results and Discussion}

\subsection{Phase transition during electrolysis \\ 3.1.1 Electrolysis of $\mathrm{Ti}_{3} \mathrm{O}_{5}$}

Figure 3(a) shows that $\mathrm{Ti}_{3} \mathrm{O}_{5}$ powder used as the cathode in the electrolysis process and XRD patterns.

According to the XRD patterns, it shows perovskites formed after electrolysis for 10 minutes and $\mathrm{Ti}_{3} \mathrm{O}_{5}$ completely reduced to $\mathrm{Ti}_{2} \mathrm{O}_{3}$. With the prolongation of the reduction time, the $\mathrm{Ti}_{2} \mathrm{O}_{3}$ is reduced to $\mathrm{Ti}_{2} \mathrm{O}$ after 1 hour and it is further 


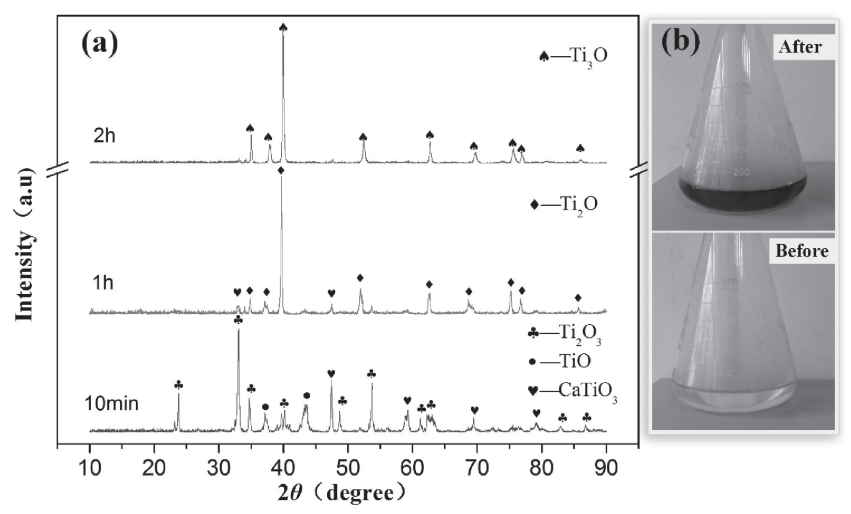

Fig. $3 \mathrm{Ti}_{3} \mathrm{O}_{5}$ used as the cathode (a) the XRD patterns of $\mathrm{Ti}_{3} \mathrm{O}_{5}$ powder at different electrolytic time; (b) Changes of Starch KI solutions.

reduced to $\mathrm{Ti}_{3} \mathrm{O}$ after 2 hours. Perovskite phase also appeared in the XRD pattern of the sample after electrolysis in 10 minutes and 2 hours. This is due to a large amount of $\mathrm{Ca}^{2+}$ from the molten $\mathrm{CaCl}_{2}$ entered the cathode after the voltage was applied between the electrodes, these $\mathrm{Ti}_{3} \mathrm{O}_{5}$ are then reduced to $\mathrm{Ti}_{2} \mathrm{O}_{3}$, with the perovskite produced as a byproduct.

When $\mathrm{Ca}^{2+}$ from the molten salt takes part in the reaction to formed perovskite in the cathode, $\mathrm{Cl}^{-}$may be forced to accumulate at the anode and finally be released as $\mathrm{Cl}_{2}$. The chlorine reacted with $\mathrm{KI}$ in the solution and replaced the iodine, so the replaced iodine produced a colour reaction with the starch in the solution. Figure 3(b) shows that the solution turns blue after electrolysis, which proves the formation of perovskite during electrolysis.

\subsubsection{Electrolysis of $\mathrm{Ti}_{2} \mathbf{O}_{3}$}

In the same way, the $\mathrm{Ti}_{2} \mathrm{O}_{3}$ powder as the cathode material, the phase compositions of partially reduced samples at different electrolysis time show in Fig. 4(a).

After the voltage was applied between the anode and cathode, the $\mathrm{Ti}_{2} \mathrm{O}_{3}$ is rapidly reduced to $\mathrm{TiO}$ in 10 minutes, and it is also accompanied by the formation of perovskite as the byproduct. $\mathrm{CaTi}_{2} \mathrm{O}_{4}$ can be found in the sample after electrolysis for 1 hour, which may be caused by chemical reaction occur between $\mathrm{TiO}$ and $\mathrm{CaTiO}_{3}$, and a part of the $\mathrm{CaTi}_{2} \mathrm{O}_{4}$ is deoxidized to form $\mathrm{Ti}_{2} \mathrm{O}$. In the XRD patterns electrolysis for 2 hour, it show $\mathrm{Ti}_{2} \mathrm{O}$ was deoxygenated to produced $\mathrm{Ti}_{3} \mathrm{O}$, and there was no $\mathrm{CaTiO}_{3}$ and $\mathrm{CaTi}_{2} \mathrm{O}_{4}$ in the

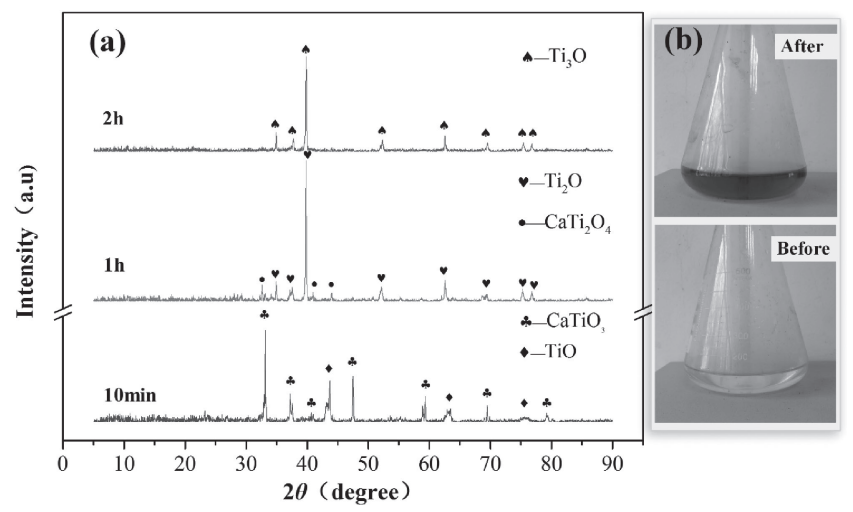

Fig. $4 \mathrm{Ti}_{2} \mathrm{O}_{3}$ used as the cathode (a) the XRD patterns of $\mathrm{Ti}_{2} \mathrm{O}_{3}$ powder at different electrolytic time; (b) Change of Starch KI solutions.

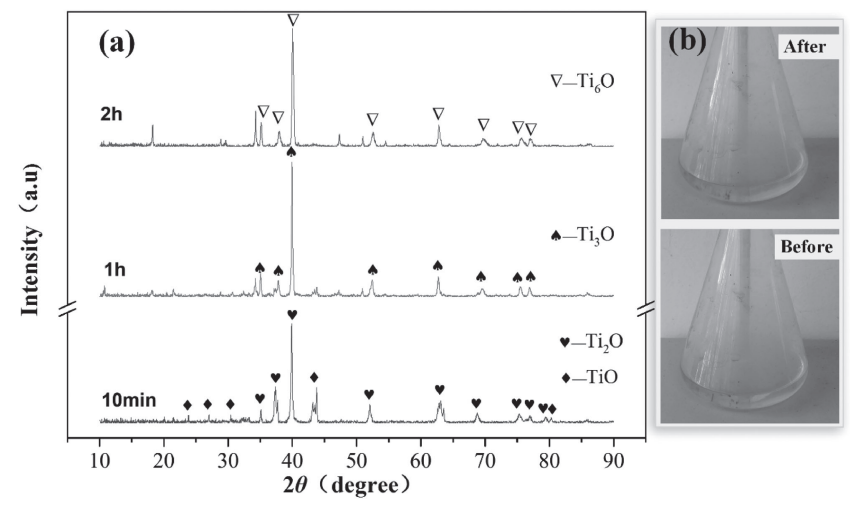

Fig. $5 \mathrm{TiO}$ used as the cathode (a) the XRD patterns of TiO powder at different electrolytic time; (b) Change of Starch KI solutions.

sample. In Fig. 4(b), the phenomenon of bluing of starch KI solutions also proves the production of perovskite in the process of electrolysis.

\subsubsection{Electrolysis of $\mathrm{TiO}$}

The result show that there is no $\mathrm{CaTiO}_{3}$ formed if $\mathrm{TiO}$ is used as the raw materials. Figure 5 shows the XRD patterns and the change of the gases released from the anode. In Fig. 5(b), the starch KI solutions also did not detect chlorine gas. Part of $\mathrm{TiO}$ has been reduced to $\mathrm{Ti}_{3} \mathrm{O}$ after 10 minutes. It was completely reduced to $\mathrm{Ti}_{3} \mathrm{O}$ in 1 hour, $\mathrm{Ti}_{6} \mathrm{O}$ was produced after 2 hours.

The results show that perovskite formed in the cathode can be avoided only by using $\mathrm{TiO}$ as the raw materials during the electrolysis. Perovskite also appeared in the cathode when $\mathrm{Ti}_{3} \mathrm{O}_{5}$ and $\mathrm{Ti}_{2} \mathrm{O}_{3}$ are used as the raw materials. Comparing the results of Fig. 3 with Fig. $4, \mathrm{CaTiO}_{3}$ is still detected in the sample after electrolysis for 1 hour using $\mathrm{Ti}_{3} \mathrm{O}_{5}$. However $\mathrm{CaTiO}_{3}$ is completely converted to $\mathrm{CaTi}_{2} \mathrm{O}_{4}$ when using $\mathrm{Ti}_{2} \mathrm{O}_{3}$. This means that using $\mathrm{Ti}_{2} \mathrm{O}_{3}$ as the raw materials produces less perovskite than that of $\mathrm{Ti}_{3} \mathrm{O}_{5}$. The results demonstrate that as the oxygen content in the cathode raw material decreases, the amount of perovskite gradually reduced and there is not perovskite formed during electrolysis TiO.

We all know that $\mathrm{CaCl}_{2}$ is easly hydrolysis in air to produce $\mathrm{CaO}$. $\mathrm{CaO}$ can be react with $\mathrm{TiO}_{2}$ formed $\mathrm{CaTiO}_{3}$. To prove that whether $\mathrm{CaTiO}_{3}$ in the cathode produces during cooling, washing or drying in air after electrolysis. The comparison experiments of with voltage and without voltage are proceeded at here.

The results in Fig. 6 show that no perovskite produced when the sample soaks in the molten $\mathrm{CaCl}_{2}$ compared with the sample electrolysized in molten $\mathrm{CaCl}_{2}$ at the same condition. It proved that perovskite in the cathode is only formed during electrolysis.

\subsection{Transformation of sample morphology during electrolysis}

In order to investigate the relationship between the changes of themorphology and the reaction of the samples during the deoxidization process, the partially reduced sample was measured by scanning electron microscope.

SEM image in Fig. 7(a) shows that there is a large number of perovskite electrolysis for $10 \mathrm{~min}$ using $\mathrm{Ti}_{3} \mathrm{O}_{5}$, 

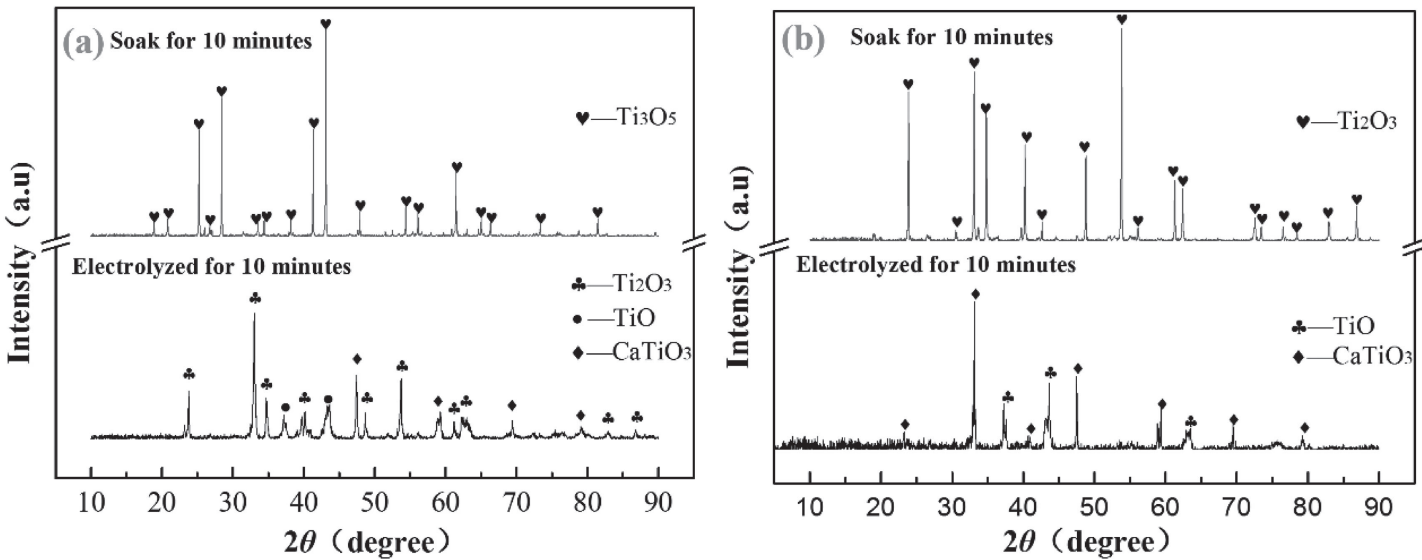

Fig. 6 (a) Comparisons of the XRD patterns of $\mathrm{Ti}_{3} \mathrm{O}_{5}$ powder electrolysis for 10 minutes and soak for 10 minutes; (b) Comparisons of the XRD patterns of $\mathrm{Ti}_{2} \mathrm{O}_{3}$ powder electrolysis for 10 minutes and soak for 10 minutes.
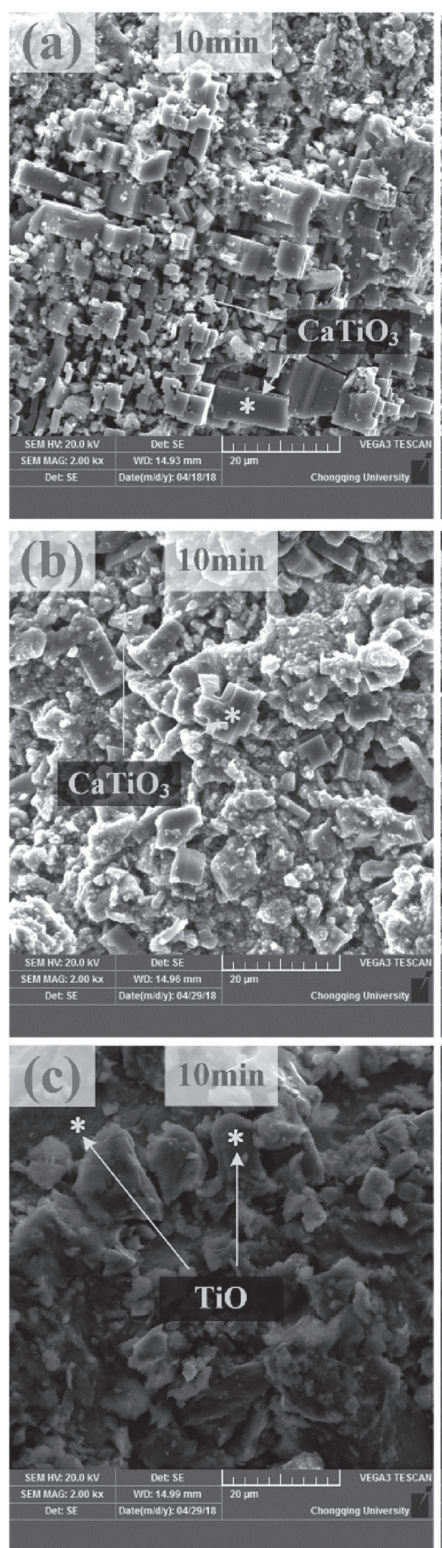
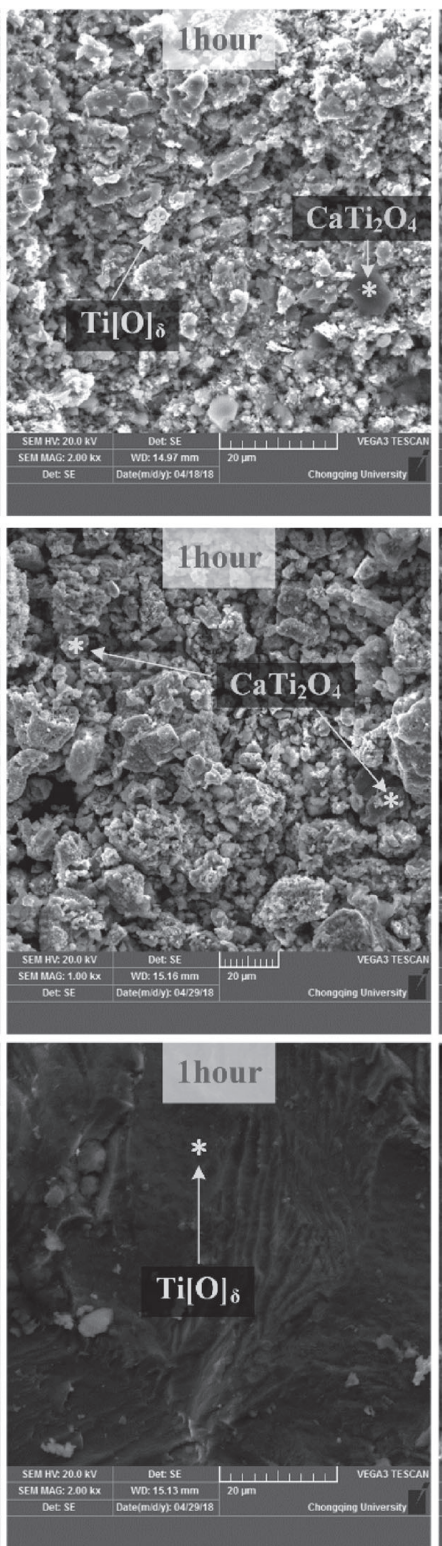
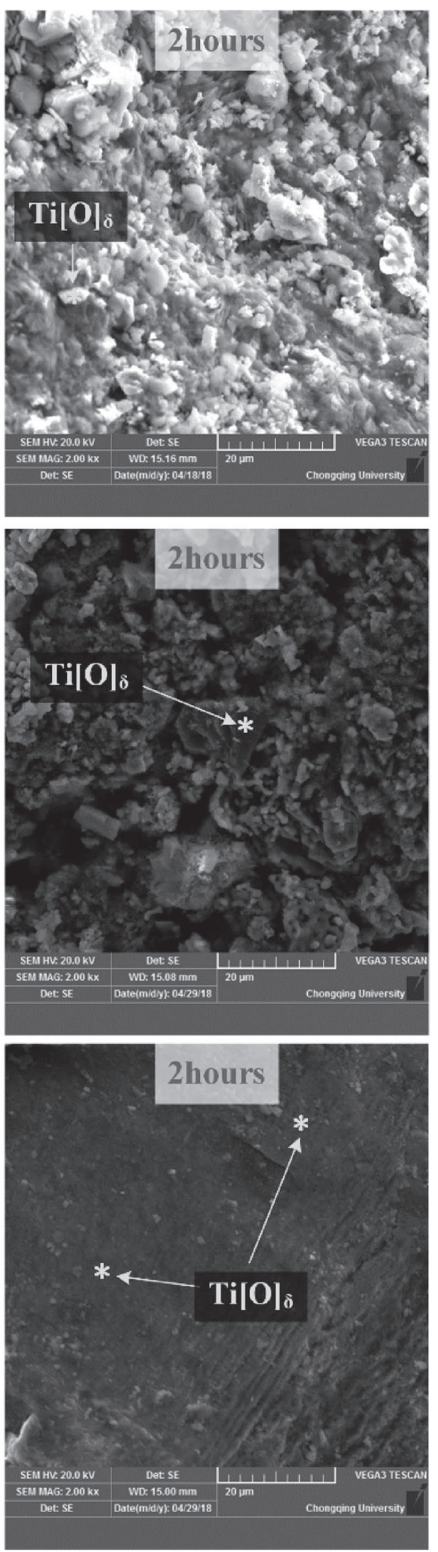

Fig. 7 SEM images using different titanium suboxides electrolysis at different time (a) using $\mathrm{Ti}_{3} \mathrm{O}_{5}$ as the raw material electrolysis for $10 \mathrm{~min}, 60 \mathrm{~min}$ and $120 \mathrm{~min}$ (b) using $\mathrm{Ti}_{2} \mathrm{O}_{3}$ as the raw material electrolysis for $10 \mathrm{~min}$, $60 \mathrm{~min}$ and $120 \mathrm{~min}$; (c) using $\mathrm{TiO}$ as the raw material electrolysis for $10 \mathrm{~min}, 60 \mathrm{~min}$ and $120 \mathrm{~min}$. 
which exhibit a crystal-like morphology and densely aligned with each other. In the initial stage of electrolysis, $\mathrm{Ti}_{3} \mathrm{O}_{5}$ reduces to $\mathrm{Ti}_{2} \mathrm{O}_{3}$, the perovskite grows rapidly with terraced structure. Schwand ${ }^{21)}$ believes that this terracing results from the $\mathrm{CaTiO}_{3}$ "attempting" to form a uniform layer around the irregularly shaped sub-oxide particles, while maintaining faceted growth and one crystallographic orientation. It can be observed that the edge of the crystal structure becomes slippery gradually in $1 \mathrm{~h}$ shown as in Fig. 7(a). The change of microstructure is due to the chemical reaction between $\mathrm{TiO}$ and $\mathrm{CaTiO}_{3}$ formed $\mathrm{CaTi}_{2} \mathrm{O}_{4}$ (reaction 3). $\mathrm{CaTiO}_{3}$ or $\mathrm{CaTi}_{2} \mathrm{O}_{4}$ was not found in the the sample electrolysis for 2 hours. It is consistent with the XRD results. Figure $7(b)$ is the SEM images using $\mathrm{Ti}_{2} \mathrm{O}_{3}$ electrolysis at different times. It can be found that the amount of perovskite produced is much when using $\mathrm{Ti}_{3} \mathrm{O}_{5}$ as the raw metarial in $10 \mathrm{~min}$. Namely, oxygen content in titanium oxides is higher amount of perovskites is more. This is consistent with the dissolution behavior expected for a faceted material, which will grow by a ledge mechanism and preferentially dissolve at the corners. ${ }^{21}$ It can be inferred that the stage of perovskite formation has ended and some perovskites have begun to react with $\mathrm{TiO}$ to form $\mathrm{CaTi}_{2} \mathrm{O}_{4}$. It is obvious that the amount of perovskite produced decreases with the decreasing of oxygen content in the raw material and the reaction proceeds to the next stage faster.

The crystal-like morphology particles not appeared in Fig. 7(c). It is consistent with the results of the XRD pattern. The microstructure shows that the structure of samples becomes denser with the decrease of oxygen content.

\section{Conclusions}

(1) Perovskites are still produced during electrolysis when both $\mathrm{Ti}_{3} \mathrm{O}_{5}$ and $\mathrm{Ti}_{2} \mathrm{O}_{3}$ were used as the raw materials. Perovskite can be avoided only when $\mathrm{TiO}$ is used as the cathode.

(2) Perovskite is mainly produced by electrochemical deoxidation process which is formed by combining $\mathrm{Ca}^{2+}$ in the molten $\mathrm{CaCl}_{2}$ with titanium oxides when the voltage is applied between the electrodes.

(3) The amount of perovskite produced decreases with the decreasing of oxygen content in the raw material, the crystal-like morphology of samples gradually weakened.

\section{Acknowledgements}

The authors gratefully acknowledge gratefully the financial support from the National Natural Science Foundation of China (Grant No. 51674054), supported by the National Key R\&D Program of China (2017YFB0603801), and supported by the Chongqing Key Laboratory of VanadiumTitanium Metallurgy and New Materials, Chongqing University, Chongqing 400044, PR China.

\section{REFERENCES}

1) G.Z. Chen, D.J. Fray and T.W. Farthing: Nature 407 (2000) 361-364.

2) C. Schwandt, G.R. Doughty and D.J. Fray: Key Eng. Mater. 436 (2010) $13-25$.

3) C. Schwandt: Min. Proc. Ext. Met. Rev. 122 (2013) 213-218.

4) R.O. Suzuki, H. Noguchi, H. Hada, S. Natsui and T. Kikuchi: Mater. Trans. 58 (2017) 341-349.

5) K. Ono and R.O. Suzuki: JOM 54 (2002) 59-61.

6) R.O. Suzuki, K. Ono and K. Teranuma: Metall. Mater. Trans. B 34 (2003) 287-295.

7) R.O. Suzuki: J. Phys. Chem. Solids 66 (2005) 461-465.

8) R.O. Suzuki and S. Fukui: Mater. Trans. 45 (2004) 1665-1671.

9) C. Schwandt and D.J. Fray: Electrochim. Acta 51 (2005) 66-76.

10) K. Dring, R. Dashwood and D. Inman: J. Electrochem. Soc. 152 (2005) E104-E113.

11) J. Mohanty, K.G. Mishra, R.K. Paramguru and B.K. Mishra: Metall. Mater. Trans. B 43 (2012) 513-518.

12) K. Jiang, X.H. Hu, M. Ma, D.H. Wang, G.H. Qiu, X.B. Jin and G.Z. Chen: Angew. Chem. Int. Ed. 45 (2006) 428-432.

13) H.L. Chen, Y. Zeng, W. Li, J.J. Peng, X.B. Jin and G.Z. Chen: Electrochem. Commun. 26 (2013) 33-36.

14) W. Li, X.B. Jin, F.L. Huang and G.Z. Chen: Angew. Chem. Int. Ed. 49 (2010) 3203-3206.

15) X.Y. Yan and D.J. Fray: Metall. Mater. Trans. B 33 (2002) 685-693.

16) G.Z. Chen and D.J. Fray: Light. Met. (2001) 1147-1151.

17) M.J. Sang, J.Y. Jung, C.S. Seo and S.W. Park: J. Alloys Compd. 440 (2007) 210-215.

18) P. Gao, X.B. Jin, D.H. Wang, X.H. Hu and G.Z. Chen: J. Electroanal. Chem. 579 (2005) 321-328.

19) D.T.L. Alexander, C. Schwandt and D.J. Fray: Electrochim. Acta 56 (2011) 3286-3295.

20) R. Bhagat, D. Dye, S.L. Raghunathan, R.J. Talling, D. Inman, B.K. Jackson, K.K. Rao and R.J. Dashwood: Acta Mater. 58 (2010) 50575062 .

21) D.T.L. Alexander, C. Schwandt and D.J. Fray: Acta Mater. 54 (2006) 2933-2944. 